\title{
Transmission performance of all-optically labelled packets using ASK/DPSK orthogonal modulation
}

Chi, Nan; Carlsson, B.; Zhang, Jianfeng; Holm-Nielsen, Pablo Villanueva; Peucheret, Christophe; Jeppesen, Palle

Published in:

Tech. Digest IEEE Laser and Electro-Optics Society Annual Meeting

Link to article, DOI:

10.1109/LEOS.2002.1133913

Publication date:

2002

Document Version

Publisher's PDF, also known as Version of record

Link back to DTU Orbit

Citation (APA):

Chi, N., Carlsson, B., Zhang, J., Holm-Nielsen, P. V., Peucheret, C., \& Jeppesen, P. (2002). Transmission performance of all-optically labelled packets using ASK/DPSK orthogonal modulation. In Tech. Digest IEEE Laser and Electro-Optics Society Annual Meeting (Vol. 1, pp. 51-52). IEEE.

https://doi.org/10.1109/LEOS.2002.1133913

\section{General rights}

Copyright and moral rights for the publications made accessible in the public portal are retained by the authors and/or other copyright owners and it is a condition of accessing publications that users recognise and abide by the legal requirements associated with these rights.

- Users may download and print one copy of any publication from the public portal for the purpose of private study or research.

- You may not further distribute the material or use it for any profit-making activity or commercial gain

- You may freely distribute the URL identifying the publication in the public portal 


\title{
Transmission Performance of All-optically labelled Packets using ASK/DPSK Orthogonal Modulation
}

\author{
Nan Chi, Birger Carlsson, Jianfeng Zhang, Pablo V. Holm-Nielsen, Christophe Peucheret, Palle Jeppesen
}

\begin{abstract}
First transmission experiment with alloptically labelled packets consisting of ASK modulated payload and orthogonally modulated DPSK label is demonstrated. The limitation of the laser linewidth and the input extinction ratio are discussed.
\end{abstract}

\section{INTRODUCTION}

All-optical label switching is of increasing interest in future packet-switched WDM networks because individual packets can be switched through an optical network element without being converted from optical to electronic format [1]. The optical label can be achieved by a modulation which is orthogonal to the intensity modulated payload, e.g. phase modulation [2] Therefore, if the wavelength is also kept as a label [1] a two-level optically labelled packet will be generated through this orthogonal modulation scheme.

Here, we report on the investigation of the transmission properties of all-optically labelled data using ASK and DPSK orthogonal modulations for the payload and label respectively. We discuss the influence of the laser linewidth and ASK extinction ratio and report the first experimental transmission of $10 \mathrm{Gbit} / \mathrm{s}$ ASK payload data with $2.5 \mathrm{Gbit} / \mathrm{s}$ DPSK label over $50 \mathrm{~km}$, clearly demonstrating the feasibility of this combined modulation formats scheme.

\section{THEORY}

Transmission of both payload and label/header is essential in packet-switched networks. The advantage of the ASK/DPSK scheme is that it carries the optical label in-band on the same wavelength as the payload. However the ASK payload will induce cross-talk on the label due to fiber nonlinearity, while the DPSK label will degrade the payload due to phase-toamplitude modulation conversion induced by the fiber chromatic dispersion. The laser phase noise is also a critical parameter for the direct detection of the DPSK label. Fig.1 shows simulation results outlining the influence of the laser linewidth at different label bit rates for a $10 \mathrm{Gbit} / \mathrm{s}$ modulated ASK payload with extinction ratio equal to $3 \mathrm{~dB}$. The maximum acceptable laser linewidth is proportional to the label bit rate with a factor of 0.04 , which means that for a 156.25 Mbit/s label, the required laser linewidth has to be below $6.25 \mathrm{MHz}$, whereas for a $2.5 \mathrm{Gbit} / \mathrm{s}$ label, the allowable laser linewidth is lower than $100 \mathrm{MHz}$. In the following experimental study, the use of a lowlinewidth external cavity laser enables to meet those requirements.

The authors are with Research Center COM, Technical University of Denmark, Lyngby DK-2800, Denmark (e-mail: nc@com.dtu.dk).

\section{EXPERIMENT}

The experimental setup is shown in Fig.2. The signal source is a wavelength tunable external cavity laser (ECL) working at $1552.5 \mathrm{~nm}$. The signal is first intensity modulated by a Mach-Zehnder modulator. The DPSK label is then impressed by the subsequent phase modulator. The transmission span consists of $50 \mathrm{~km}$ standard fiber (SMF) followed by $8.6 \mathrm{~km}$ dispersion compensating fiber (DCF). At the receiver, a fibre one bit delay demodulator is used for the DPSK label. The measured receiver sensitivities of the payload and the label as a function of the extinction ratio are shown in Fig.3. As expected, we observe a trade off between the extinction ratio requirements for the payload and the label. A degraded extinction ratio is known to result in penalty for the payload, whereas the extinction ratio should not be too large so that the phase modulated label can be recovered. An extinction ratio of $2.84 \mathrm{~dB}$ was used for transmission. The signal power at the SMF input was set to $6 \mathrm{dBm}$. After transmission, the label shows a low power penalty, which is below $1 \mathrm{~dB}$. However, the payload has a relatively large penalty up to $8 \mathrm{~dB}$ (see Fig.4) because of the low extinction ratio. The eye diagrams for the original data and the transmitted signal are shown in Fig.5. Due to the intrinsic amplitude fluctuation of the intensity modulated payload, the received label eye diagram has a multi-level structure. Both the payload and the label can be obtained error-free after $50 \mathrm{~km}$ transmission.

\section{CONCLUSION}

We have demonstrated the feasibility of using orthogonal ASK/DPSK modulation for all-optical labelling. The signal requirements in terms of extinction ratio and laser linewidth have been analysed. Error-free transmission of both payload and label has been demonstrated over a $50 \mathrm{~km}$ SMF dispersion compensated span.

\section{ACKNOWLEDGMENT}

This work is performed in the IST STOLAS (Switching Technologies for Optically Labelled Signals) project supported by the European Commission.

\section{REFERENCES}

[1] N. Ghani, 'Lambda-labeling: a framework for IPover-WDM using MPLS', Optical Networks Magazine, 2000,1, (2), pp.45-58

[2] T.Koonen, G.Morthier, J.Jennen, H. D.Waardt, P. Demeester, 'Optical packet routing in IP-overWDM networks deploying two-level optical labeling', 2001, Proc. ECOC'01 


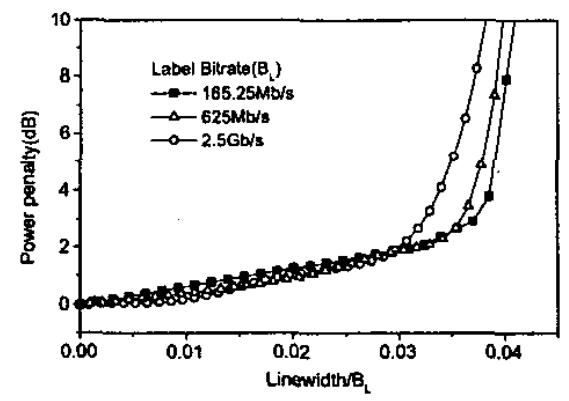

Fig.1.Simulater power penalty vs. laser linewidth normalised to the label bit-rate for $3 \mathrm{~dB}$ extinction ratio at different label bit rates.

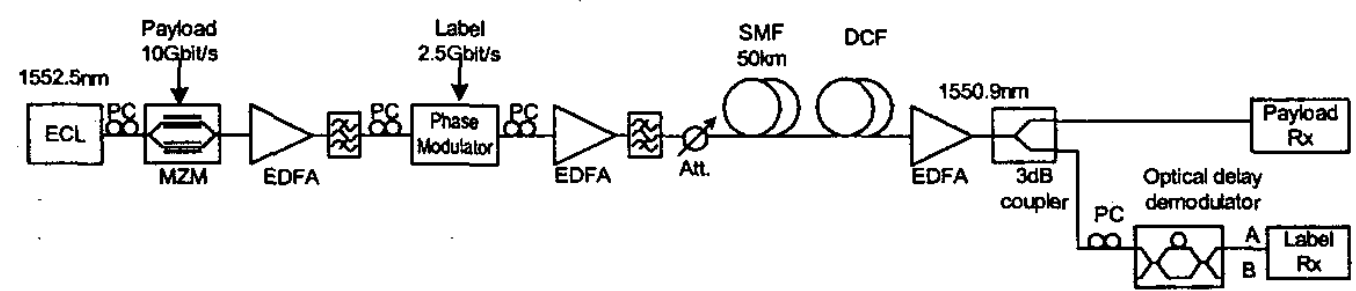

Fig.2 Experimental setup. ECL: external cavity laser, MZM: Mach-Zehnder modulator, PC: polarization controller, Att.: attenuator.

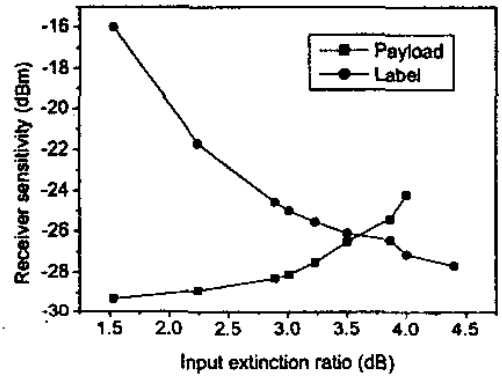

Fig.3 Measured receiver sensitivity vs. input extinction ratio for the label and the payload.

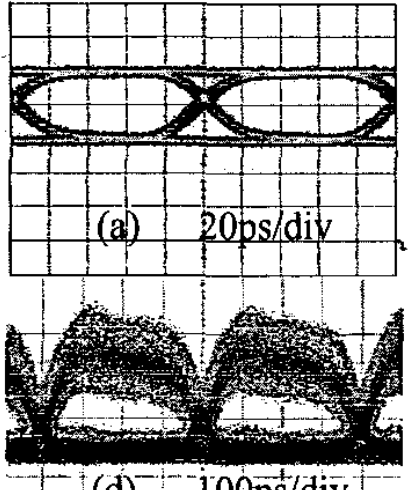

(d) $-100 \mathrm{ps} / \mathrm{div}$

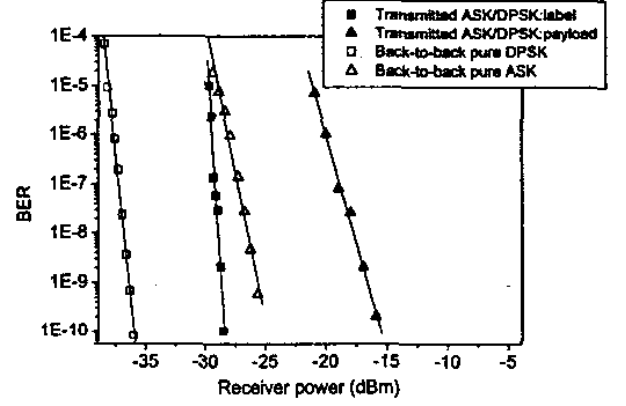

Fig.4 Measured BER performance for back-to-back (single modulation) and after transmission (orthogonal modulation).

Fig.5 Measured eye diagram for (a) original ASK signal at $10 \mathrm{Gbit}$ s, (b) back-to-back payload, (c) payload after transmission over $50 \mathrm{~km} \mathrm{SMF,}$ (d) back-to-back label at $2.5 \mathrm{Gbit}$, (e) label after $50 \mathrm{~km}$ transmission, (f) pure DPSK signal after $50 \mathrm{~km}$ transmission. 